\title{
Practitioner Learning in the Intersections Between Science and Language
}

\author{
Valeria M. Cabello ${ }^{1}$ I Ivan Salinas Barrios ${ }^{2} \cdot$ David Geelan $^{3}$ (D
}

Published online: 4 June 2019

(C) Springer Nature B.V. 2019

A recent panel celebrating the 10th anniversary of the University of Chile's Institute of Advanced Research in Education featured one of the awardees of the Global Teacher Prize (Varkey Foundation 2019). In his presentation, he recognized that, in seeking to enhance his own teaching, he became an "improvised researcher", and came to acknowledge the importance of connecting research to practice. What sorts of knowledge would become accessible to our field if we organized the efforts of all of those doing this "improvised" research? What kinds of new avenues, new questions, new approaches for understanding practice, new ways of circulating knowledge, and new commitments for science education would open up? How would these differ qualitatively from the questions we have now about learning, about teaching, about science? It might be time to engage those questions.

Educational researchers around the globe seem to be eager to engage in questions with the potential to make new sense of the present and future. This year, 2019, marks the 50th anniversary of the Australasian Science Education Research Association. Reflecting on half a century of science education research might spark motivation to review the field's achievements and future directions. The 2019 conference of NARST - a worldwide organization for improving science teaching and learning through research - chose the theme "Creating and sustaining collective activism through science education research". The Chilean Society of Science Education has called its 2019 conference "Science Education for Social Justice". The

This is the Editorial for the Special Issue of RISE, August 2019, on practitioner learning in science and education

David Geelan

d.geelan@griffith.edu.au

Valeria M. Cabello

vmcabello@uc.cl

Ivan Salinas Barrios

iedusal@uchile.cl

1 Facultad de Educación, Pontificia Universidad Católica de Chile, Santiago, Chile

2 Centro de Investigación Avanzada en Educación, Departamento de Estudios Pedagógicos, Universidad de Chile, Santiago, Chile

3 School of Education and Professional Studies, Griffith University, Parklands Drive, Southport, Queensland 4222, Australia 
American Educational Research Association 2019 annual conference theme was "Leveraging Education Research in a "Post-Truth" Era: Multimodal Narratives to Democratize Evidence". These themes illustrate trends in efforts of researchers as they question our present historical moment, its conditions and assumptions. In focusing on activism, on social justice, on democratization as concerns for educational researchers, what are we doing in the science education field? What directions are these efforts showing in our field? We wanted to engage in these sorts of questions from a particular place: science education research from the perspectives of those who are engaging it in classrooms.

The current human experience of schooling, with rapid technological development, and as a site of globalization and its opportunities and contradictions in many different contexts, can fuel new questions and new forms of inquiring about them. In a recent book, Joel Spring (2019) claims that the Western model of schooling has spread throughout the world and has contributed to creating a consumer culture, which can lead to actions that destroy the natural environment and diminish feelings of compassion and empathy. As today's globalized science education researchers and citizens, we understand that a vision of dialogue is critical to provide mutual understandings about our different ways of knowing and the forms in which they express in our contexts. We recognize that dialogue requires language, and science should be concerned with language for increasing dialogue.

For this Special Issue, we crafted a call grounded in our own informed, but also intuitive, interpretation of two important needs: (1) language and (2) practitioner learning in science education. At the time of this crafting, we were engaged in a research collaboration focused on understanding the role of explanations in physics teaching and science teacher education. While getting to know each other, we realized the breadth of our formative experiences in teaching and teacher education: Chile, Australia, the United States, Scotland, and Canada. Our conversations expanded beyond the topic of explanations in teacher education, and into issues of science education in general, and the ways in which we understand its main concerns. As researchers and citizens, we are preoccupied with both highlighting the role of science as a humane project for the peoples of the world and understanding its connections with the whole of human experience. That is to say, this is a pedagogical project.

We wanted to provoke a discussion about who is called upon to talk about these understandings, whose voices matter. We decided to invite researchers who see themselves as practitioners, and practitioners who see themselves as researchers, to show how they are learning about language in science and science in language because, as mentioned before, language is key for dialogue, and dialogue is essential in science education (Lemke 1990). We wanted to push ourselves into a space where, as researchers, we do not just observe phenomena and people within educational context from the "outside" but also observe ourselves and listen to the voices of those who are traditionally invited to be researched but not to be active in researching, in producing and reporting knowledge. That is why we called this issue "practitioner learning".

Knowing that the relationships between theory and practice into research are subject to debate (Ashwin 2012; Jarvis 1999), we consider that two kinds of perspectives might come into play when conducting research: etic perspectives derive from using theoretical frameworks as light with which to analyze the field, while emic perspectives are more closely connected to the meanings and interpretations held by the protagonists of a researched social reality (Guzmán-Valenzuela 2016). Practitioner research in educational contexts, in our view, is applied research rooted in practices, problems or challenges that - in this case - educators face in their daily work and that affect their professional practice (Cochran-Smith and Lytle 
2009). In this kind of research, practitioners conduct a process of inquiry, either by themselves as "insiders", or with help from university-based scholars, to construct new insights to inform practitioner learning about addressing science and language issues.

Understanding the complex, dynamic interactions between language from science and language in science classrooms has been an important concern for science education researchers in recent decades. Scientists' work and practices are infused with certain forms of language that require reflection and transformation when adapting them for classroom practice. Some authors have described science as being a language itself, or having its own language (e.g., Bruna and Gomez 2009; Darian 2003; Lemke 1990; Reeves 2005; Roth 2005). This has moved the field of science education research to be increasingly aware of the role of language in science classrooms. Extensive research in both classroom discourse and scientific discourse shows that there are persistent discursive practices in classrooms that may conflict with what we know about authentic scientific practices and, conversely, conflict with students' home languages. There are now well-supported reasons to think that differences in students' science achievement in part relate to differential uptakes of language and discourse used in classrooms, or to a "language gap" (Graff 1999; Hull 1985; Gee 2005).

One way of theorizing the gap in relation to language and science is through the concept of social languages (Gee 2005, 2008), which highlights the idea that, within a language, there are sublanguages or variations that depend on who is talking and what the person talking is doing. One individual may use different social languages in different contexts. Scientists' language in scientific contexts and teachers' science language in schools are forms of social languages. The ability and disposition of a person to use a social language, and to become involved in the practices associated with the users of that language, is at the centre of learning academic languages in school (Gee 2005). This is something we definitely look into when our work as science educators is to intervene in the intersections between science language as used in science and home language as used in schools.

In traditional schooling, schools tend to favour and reward those whose social languages are most like academic languages. They may be indifferent to or punish users of social languages that are unlike the academic ones. The more a student's home language models the academic languages of schools, the more possibilities there are for the student to be rewarded and succeed in school. When students' home traditions have different orality structures or emphasize different forms of narrative and grammatical construction than do academic social languages, developing skills and commitment on the part of a child to use academic languages is more difficult. Given the increasing diversity of home languages present in schools, the main implication for science education is that teaching science becomes more challenging. In today's increasingly diverse classrooms, in both cultural and linguistic terms, these challenges acquire a global nature.

For science teachers, these cultural and linguistic differences have a clear expression and material impact on the instructional decisions they make in and out of the classroom. One of the challenges of teaching science in diverse classrooms lies in the meaning-making processes students need to experience in order to understand the language of science (Kuipers et al. 2009). Science teachers who share their students' languages and cultures are likely to relate in more meaningful ways to their students' prior experiences (Fradd and Lee 1999), and bilingual teachers are more prone to propose contextualized science instruction in classrooms (Tolbert and Knox 2016). There are many challenges, however, as practitioners seek to consider the "home-classroom language gap" and the language of science in their science teaching practices (Lee et al. 2007). Teaching science becomes a matter not only of cognitive and 
procedural complexity but also of understanding and productively addressing the language differences that exist in a diverse classroom. These language differences entail cultural differences, which in turn makes for a more complex science education space.

While researchers in academic contexts have advanced the study of classroom complexities, we contend that practitioners should have a stronger voice in the conversation. Research into the use of language in science classrooms has been productive but has most often been conducted by university science education academics, doing research "on" teachers, students and classrooms in schools (e.g., Hodson 2009; McKinley et al. 1992; Wellington and Osborne 2001). In order to deepen and strengthen the voice of practitioners in the inquiry, we need to strengthen research in which practitioners conduct research "for" and "by" classroom practice. Teachers and other practitioners in classrooms should incorporate their voice in understanding their practice and sharing a dialogue with what we now, as a field, know. Examples of such research can be found in the literature, as well as frameworks to think about doing it (e.g., see Cochran-Smith and Lytle 2009; Capobianco and Feldman 2010; González-Weil et al. 2014; Salinas et al. 2017). When thinking about these examples and encouraging these frameworks, we sought to provide a space in which several forms of inquiry could be shown. At the core of these forms of inquiry, there is a connection to practice, to encouraging the systematic recording of data of practice, to analyzing and providing clues that explain how these practices come to be and what is needed to change or transform them with commitments to student learning. Our intention with this Special Issue was to motivate practitioners and researchers to explore a range of ways to report their learning about their practice.

For this Special Issue, we called for papers reporting studies in which the practices of practitioners and their own insights into those practices were placed at the centre. We also encouraged thinking about these practices that situated them within the demands of addressing the issues of language in science classrooms, or in the intersection of science and language, broadly conceived. The articles submitted have different balances between academic research and classroom practitioner approaches. The resulting selection of articles is a blend in which the reader will find researchers addressing questions of teacher learning in the intersections of students learning science and language, or the study of this intersection using data of practice. The papers provide a breadth of methodological approaches, as well as a range of ideological questions, for understanding our role as "language educators" when focusing on science learning for our students. We hope that this collection will offer the reader new ways of approaching a political commitment to highlighting practitioners' voices in the construction of knowledge for science education endeavours.

As an editorial team, it was our intention to create the space for the field to ask questions about how we construct knowledge in and for science education and what the role of practitioners is and should be. In some respects, we see ourselves as practitioners and call for a systematic approach to understanding not only the practices of others but our own practices as well, in systematic and critical ways. We also see science as a culture, which implies that classrooms become a space where there is an intercultural conflict. In researching that conflict, new voices should come into the conversation. We think that this collection of papers contributes to this endeavour.

The papers fall loosely into three clusters, composed of four papers each. The first cluster is focused on what has been learned and can be shared when practitioners - both teachers in school classrooms and teacher educators in universities - inquire into their own practices in relation to the use of language in science education, and the ways in which teachers develop expertise. 
Xavier Fazio and Tiffany Lynn Gallagher advocate Design-Based Research to facilitate professional learning when integrating language and science in order to have a positive impact on student achievement in both developing language and learning science. They also show the complexities of collecting extensive amounts of data from practice, including views from practitioners as well as student science achievement data. This work summarizes a rich agenda for doing research collaboratively and with a focus on practice, learning about it from as many sources as possible. The authors call for an effort to research the integration of language and science as a way to support the development of multimodal resources for science learning. Some of the questions that follow for future research development of this sort of data are the following: How are teachers participating in the discussion of the student achievement data? What challenges should we face as we extend, deepen and strengthen collaborations with teachers for understanding the connections between science and language in practice? How do we define "efficacy" when researching collaboratively with teachers? Would that lead to other views about understanding achievement in science education?

In an educational world increasingly dominated by high-stakes standardized testing, Cory Buxton, Ruth Harman, Lourdes Cardozo-Gaibisso, Lei Jiang, Khanh Bui and Martha Allexsaht-Snider challenge this approach and offer new perspectives for thinking about assessment in science from sociocultural perspectives. As a team of researchers and teachers, they explore their understandings about creating resources for integrating science and language, as well as the understandings of students in the teachers' classes. They seek to understand what is gained or learned about integrating science and language when analyzing students' responses to assessment responses. In doing so, they rely on fostering a dialogic perspective on science language development in classrooms, emphasizing the value of the linguistic resources students bring to the science classrooms. Teachers learn by participating in integrating teams in which they analyze data gathered in their classrooms, focusing on students' learning.

Richard Williams, Rose Pringle and Karen Kilgore provide an example of how, in practice, a language "issue" - teaching science to English language learners - becomes a language "opportunity" after reflection and study on the part of the practitioner, searching for a strategy to include his/her students whose first language was not English in learning science. The spirit and the ways in which this exploration is presented allows us, as researchers, to make visible the day-to-day inquiries that might occupy practitioners' quotidian ways of facing issues of science education practice and reveal the strong pedagogical commitments that drive teachers' interest in learning from practice. The paper puts forward questions about how we make sense of collaborations among academic researchers and practitioner researchers, challenging traditional approaches to educational research. Additionally, various insights are presented regarding intentionally teaching vocabulary strategies to students for increasing knowledge from/for the practice of science education and therefore students' learning.

Sara Raven and Gretchen Whitman's paper is a provoking one for science educators and researchers. It provokes because it calls our attention to how deaf and hard-of-hearing students are often served by less well-prepared teachers (in terms of skills and approaches to serving these students), and hence have less opportunities to participate in science and learn science. They consider that science learning is inextricably tied to two aspects of students' lives: literacy and culture. The authors highlight the fact that serving the deaf and hard-of-hearing peoples of the world poses a clear challenge to learning science in the ways we are used to understanding it. In our commitment to advancing research, this paper provides a space to expand the field's learning with more energy and generosity and informs practitioners' 
learning. Identifying the challenges of better serving deaf and hard-of-hearing students in science education as an opportunity to collaboratively pursue creative advances in pedagogy and in our thinking about language and learning science is far more powerful than taking a "deficit" perspective toward the learning of these students and the teaching they receive.

The second cluster of papers is broadly focused on methods and methodologies: what are the processes and approaches that have been used to inquire into the ways in which teachers develop and exercise their professional knowledge and professional judgement in relation to the use of language in science education? Can these approaches be adopted by others seeking to inquire into and improve their own knowledge and their own practices?

In his paper, Karl Jung writes about an experience in a coaching partnership with the goal of understanding successes and challenges in implementing language scaffolding in science instruction. In doing so, he develops a classroom teaching experiment, which is a collaboration between Mr. Mills, a classroom teacher, and the author, a researcher. The author differentiates the study from action-research and from Design-Based Research, given that Mr. Mills did not participate in the analysis, and the cycles of iteration were short and were focused on specific instructional activities. Extensive data of practice were collected in this study. This work challenges our thinking about how we frame science learning differently or similarly to language learning. The author answers the question: What successes and challenges are experienced by an elementary science teacher while preparing and implementing instruction for science academic language through an instructional coaching partnership? Throughout the article, he shows readers how retrospective analysis empowers the voices of practitioners. Some of the questions that this work raises include the following: How are we to think about our role as researchers and practitioners of language and science integration? Should we consider ourselves - as science educators-language educators as well? What is research saying about this integration?

Carla Meskill and Alan Oliviera's article reports a study in which teachers of science and teachers of English were brought together in a professional development workshop, with the intention of sharing professional knowledge and skills to better prepare all teachers to support learners for whom English is a second or other language. The paper follows one pair of teachers - a chemistry teacher and a Teacher of English as a Second or Other Language (TESOL) - as they collaborate to develop, deliver and reflect on lessons. Participants shared ideas around language, science content, educational technology and assessment. The authors suggest that workshops pairing language teachers with teachers of content subjects such as science have the potential to better serve English language learners in their science education.

Gale Seiler and Hildah Kwamboka invite us to look into classrooms as cultural spaces. They see science and language integration from a neoindigenous perspective, where issues that are usually avoided in our common discussions about science come to salience. Particularly, the idea of science - and language - as part of a colonizing effort is discussed in a refreshing and necessary way for the field. Using a self-study methodology based on practitioner research, the authors engage in a reflective process about their practice that is richly informed by a de-colonizing perspective on science and schooling. This work can provide a different perspective on how we report research and of inquiry issues around language in science, since the contextual nature of some of the linguistic experiences students have in schools might be explained beyond the scope of our science teachings. What should we do with our understandings of science education when perspectives about its role in colonizing-e.g., oppressing - becomes visible? How are we to think about methodologies for inquiring into science and language when de-colonizing perspectives become important for educators' 
practices? These are some of the questions that arise from reading this work focused on the voice and journey of a Biology in-service teacher.

Diego Román, Karla del Rosal and Deni Basaraba invite readers to understand the complexity of emerging explanations in science in view of their role as informal formative assessment. Their work represents an example of the complexities inherent in studying classroom interactions between student and teachers and managing the data drawn from practice in analyzes that could favour the development of new knowledge. Teachers' awareness of the role of linguistic interactions is discussed as a critical element for researching and creating classrooms that are more responsive to students from linguistically diverse backgrounds. This study broadens the analysis of explanations in science education as both an input and a response in the frame of iterative processes to promote students' learning.

The final group of four papers shifts to focus on teacher education. Helping to prepare beginning teachers in teacher education programs to use language in science education, in ways including explanation and teaching in context, is an area in which there remains much research work to be done, and we hope that this Special Issue contributes to the knowledge base and to opening up questions and sharing methods for further inquiry.

The paper by Sara Tolbert, Corey Knox and Ivan Salinas explores their work as practitioners of science teacher education in fostering practices that are more inclusive of students' linguistic backgrounds through contextualization in science teaching. In their work, they acknowledge the complexities inherent in changing a practice and contextualizing science instruction. However, they also point to the benefits for all students in thinking about the context in science instruction, linking contextualizing science activity to language acquisition and science learning. This approach has particular benefits for those who are learning in a language different from their home language. This work presents an orientative schema to support practitioners to frame, adapt and apply authentic scientific practices in the classroom, with valuable reflections from the practice of two science teachers about emergent decisions taken into the classroom to promote language and science learning.

Valeria Cabello, Costanza Real and Maria Antonietta Impedovo write about the conceptual explanations developed and delivered by science teacher education students. They found that explanations drew on the knowledge of both language and science content, but that they tended to be considered by the teacher education students to be finished artefacts that were in some sense "static". An explanation was understood as a textual "product" that, once it had been developed, would simply be delivered in a broadcast manner to school students. Explanations did not seem to address the nature of knowledge or the nature of science, or to reflect the dynamic and contested nature of scientific knowledge. The findings of this work relate to a distinction drawn by Kulgemeyer and Riese (2018) between "explanation" as a (temporarily) static artefact and "explaining" as the dynamic process of actively delivering an explanation to students, listening to them, gaining feedback from them on their learning and adapting the explanation as required to help build students' understanding. This paper considers the implications for teacher education and for developing beginning science teachers as professionals in relation to explanations, and shares recommendations for future research and for teacher education programs.

Ainoa Marzábal, Cristian Merino, Patricia Moreira and Virginia Delgado continue the focus on teacher explanations, in the context of chemistry teacher education students. They compared student teachers' explanations for a range of chemistry concepts and explored similarities and differences. The authors found that the development of the discursive elements of the 
professional activity of explaining could be taught using workshops; however, the contentknowledge elements were more difficult to develop. Thus, simply having deeper content knowledge was necessary but not sufficient to allow high-quality explanations to be developed. The authors advocate for a recursive process of developing, delivering, reflecting on and making quality judgements about explanations, on multiple occasions throughout a teacher education program as an approach for developing professional knowledge and skill in this area.

Carol Joglar and Sandra Rojas-Rojas continue the focus on teacher education, but shift gears to questioning in science. They conducted a three-phase teacher reflection workshop, including meetings, video, classroom teaching sessions and reflective conversations, with teachers from a range of science subject areas. Intriguingly, they found that, while the obstacles to being able to deliver high-quality questions identified by the participants early in the cycle were focused on procedural elements, as the reflection workshop proceeded their concerns shifted to more epistemological issues. Participating teachers increasingly developed the ability to critically analyze the issues with their questions and to develop strategies to overcome the obstacles they identified to improve their questioning practices.

The issues of science and language in science classrooms are not new in science education research (e.g., Lemke 1990; McKinley et al. 1992), but we hope that the additional focus on practitioner learning that the authors of the papers in this Special Issue have brought to their work both contributes to new knowledge in science education and provokes questions, approaches and values with the potential to lead to much more collaborative, disciplined inquiry in teacher education programs and school science classrooms, with the goal of making science education more engaging, accessible and meaningful. We strongly believe that a mix of theory and practice-guided research is possible and desirable in order to construct new knowledge from practice and nurture learning trajectories of practitioners in science education.

Funding Information The authors acknowledge funding from CONICYT-Chile's grant REDES150100 through Programa de Cooperación Internacional that has favoured our research collaboration. Support from PIA-CONICYT Basal Funds for Centers of Excellence Project FB0003 is also gratefully acknowledged.

\section{References}

Ashwin, P. (2012). How often are theories developed through empirical research into higher education? Studies in Higher Education, 37(8), 941-955. https://doi.org/10.1080/03075079.2011.557426.

Bruna, K. R., \& Gomez, K. (2009). The work of language in multicultural classrooms: Talking science, writing science. New York, NY: Routledge.

Capobianco, B. M., \& Feldman, A. (2010). Repositioning teacher action research in science teacher education. Journal of Science Teacher Education, 21(8), 909-915. https://doi.org/10.1007/s10972-010-9219-7.

Cochran-Smith, M., \& Lytle, S. L. (2009). Inquiry as stance: practitioner research for the next generation. New York, NY: Teachers College Press.

Darian, S. (2003). Understanding the language of science. Austin, TX: University of Texas Press.

Fradd, S. H., \& Lee, O. (1999). Teachers' role in promoting science inquiry in students from diverse language backgrounds. Educational Researcher, 18(6), 14-20.

Gee, J. P. (2005). Language in the science classroom: academic social languages as the heart of school-based literacy. In R. K. Yerrik \& W. Roth (Eds.), Establishing scientific classroom discourse communities: multiple voices of teaching and learning research (pp. 19-37). Mahwah, NJ: Lawerence Erlbaum Associates.

Gee, J. P. (2008). Social linguistics and literacies. Trowbridge, Wiltshire: Routledge.

González-Weil, C., Gómez, M., Ahumada, G., Bravo, P., Salinas, E., Avilés, D., Pérez, J. L., Santana, J. (2014). Principios de Desarrollo Profesional Docente construidos por y para Profesores de Ciencia: una propuesta sustentable que emerge desde la indagación de las propias prácticas. (Professional development principles 
constructed by and for science teachers: a sustainable proposal emerging from inquiry about practices of one own) Estudios Pedagógicos, XL (Número Especial 1), 105-126.

Graff, G. (1999). The academic language gap. The Clearing House, 72(3), 140-142. https://doi.org/10.1080 /00098659909599614.

Guzmán-Valenzuela, C. (2016). Connecting theory and practice in qualitative research. In J. Huisman \& M. Tight (Eds.), Theory and method in higher education research (Vol. 2, pp. 115-133). England: Emerald Group Publishing Limited. https://doi.org/10.1108/S2056-375220160000002006.

Hodson, D. (2009). Teaching and learning about science: language, theories, methods, history, traditions and values. The Netherlands: Brill Sense.

Hull, R. (1985). The language gap: how classroom dialogue fails. New York, NY: Methuen.

Jarvis, P. (1999). The practitioner-researcher. Developing theory from practice. San Francisco, C.A.: Jossey-Bass Publishers.

Kuipers, J., Viechnicki, G. B., Massoud, L. A., \& Wright, L. J. (2009). Science, culture and equity in curriculum: an ethnographic approach to the study of a highly-rated curriculum unit. In K. R. Bruna \& K. Gomez (Eds.), The work of language in multicultural classrooms: talking science, writing science (pp. 241-268). New York, NY: Routledge.

Kulgemeyer, C., \& Riese, J. (2018). From professional knowledge to professional performance: the impact of CK and PCK on teaching quality in explaining situations. Journal of Research in Science Teaching, 55(10), 1393-1418. https://doi.org/10.1002/tea.21457.

Lee, O., Luykx, A., Buxton, C., \& Shaver, A. (2007). The challenge of altering elementary school teachers' beliefs and practices regarding linguistic and cultural diversity in science instruction. Journal of Research in Science Teaching, 44(9), 1269-1291. https://doi.org/10.1002/tea.20198.

Lemke, J. L. (1990). Talking science: language, learning, and values. Westport, CT: Ablex Publishing Corporation.

McKinley, E., McPherson Waiti, P. M., \& Bell, B. (1992). Language, culture and science education. International Journal of Science Education, 14(5), 579-595. https://doi.org/10.1080/0950069920140508.

Reeves, C. (2005). The language of science. Intertext. New York, NY: Routledge.

Roth, W.-M. (2005). Talking science: language and learning in science classrooms. Lanham, MD: Rowman \& Littlefield Publishers.

Salinas, I., González, N., \& Fernández, L. (2017). Indagación narrativa de aula: casos de innovación en educación científica. (Classroom narrative inquiry: innovation cases in science education). Concepción, Chile: Escaparate Ediciones.

Spring, J. (2019). Global impacts of the Western school model: corporatization, alienation, consumerism. New York, NY: Routledge.

Tolbert, S., \& Knox, C. (2016). "They might know a lot of things that I don't know": investigating differences in preservice teachers' ideas about contextualizing science instruction in multilingual classrooms. International Journal of Science Education, 38(7), 1133-1149. https://doi.org/10.1080/09500693.2016.1183266.

Varkey Foundation. (2019). Changing Lives Through Education. https://www.varkeyfoundation.org. Accessed 10 May 2019.

Wellington, J., \& Osborne, J. (2001). Language and literacy in science education. UK: McGraw-Hill Education.

Publisher's Note Springer Nature remains neutral with regard to jurisdictional claims in published maps and institutional affiliations. 